\title{
LA DEFENSA DEL PATRIMONIO FORESTAL PÚBLICO EN LA COMUNIDAD VALENCIANA
}

\author{
POR \\ CRISTINA MONTIEL MOLINA
}

Una de las principales misiones del cuerpo facultativo de montes, desde la fecha de su fundación, ha sido la defensa del patrimonio forestal público contra los intentos de usurpación protagonizados por particulares y la degradación natural de los mismos ${ }^{1}$. Las actuaciones llevadas a cabo por los forestales en este sentido se han concretado, básicamente, en la excepción de la venta o declaración de utilidad pública de los predios públicos y en la recuperación de las fincas de dominio privado enclavadas en los montes estatales y municipales.

El primero de los aspectos de la política de defensa patrimonial ha sido particularmente atendido durante los últimos decenios por la relación que le vincula a la política de adquisiciones inaugurada en 1941 por el Patrimonio Forestal del Estado. Son, en efecto, numerosas las declaraciones de utilidad pública que, durante las décadas de los años setenta y ochenta han sido aprobadas en la provincia de Castellón, así como las recientes inclusiones que se han producido en los Catálogos de Montes de Utilidad Pública de las provincias de Valencia y Alicante. La mayor parte de estos predios proceden de la

1 ICONA: Comentarios y actualidad del informe de la Junta Consultiva de Montes (Ley 1 mayo 1855), Madrid, MAPA, 1987.

Cristina Montiel Molina. Instituto Universitario de Geografía de Alicante. 
agrupación de fincas adquiridas por el organismo correspondiente, así como del estudio y reconocimiento de montes que habían sido durante largo tiempo ignorados por los Distritos Forestales.

Aunque la adquisición de montes, que en algunos casos fueron enajenados en aplicación de las disposiciones desamortizadoras, es el origen más frecuente de las nuevas inclusiones en el Catálogo, a fines del siglo pasado fue asimismo considerable el incremento de superficie forestal pública a resultas de la incorporación al Catálogo de montes hasta entonces desconocidos por la Administración. En las Memorias de Reconocimiento de Montes Públicos elaboradas durante el último tercio del siglo pasado, solía hacerse constar los problemas que hallaba el ingeniero para definir y acotar aquellos predios, ante la carencia absoluta de información sobre su existencia y características ${ }^{2}$. Pero, sin duda, la recuperación y el esclarecimiento de la situación legal de las fincas usurpadas por los particulares a los montes públicos, procedentes en su mayoría de roturaciones arbitrarias dieciochescas y decimonónicas que en algunos casos habían logrado legitimar sus poseedores, era la tarea que entrañaba mayor dificultad.

La arbitrariedad de dominio de las fincas particulares enclavadas en montes públicos

La conflictividad de los enclavados y la necesidad de tratar el tema con habilidad y destreza han sido puestos de manifiesto por cuantos han tenido que resolver esta problemática con motivo de la ejecución del deslinde o amojonamiento de un monte público ${ }^{3}$. Además, el tratamiento de las cuestiones relacionadas con los enclavados ha sido particularmente complejo en el caso de los montes municipales, donde no sólo importa la disposición de los poseedores y propietarios a facilitar el saneamiento del estado legal de los predios públi$\cos { }^{4}$, sino también la propia colaboración de los ayuntamientos. Esta se ha encontrado en muchas ocasiones condicionada por el mismo in-

\footnotetext{
2 Archivo de la Unidad Forestal de Castellón (AUFC): Expediente del monte de utilidad pública n. ${ }^{\circ} 14$

3 Archivo de la Unidad Forestal de Valencia (AUFV): Expediente del monte de utilidad pública n. ${ }^{\circ} 16$.

4 AUFC: Expediente del monte de utilidad pública n. 22.
} 
terés colectivo del municipio por defender la titularidad pública de los terrenos forestales, produciéndose, por tanto, una coincidencia positiva entre los propósitos de la municipalidad y los de la Administración Forestal que ha permitido, en muchos casos, evitar la pérdida del suelo forestal público ${ }^{5}$.

En otras ocasiones, sin embargo, la ilegalidad de las posesiones particulares enclavadas en los predios públicos, en su mayoría procedentes de roturaciones arbitrarias, se ha consolidado al amparo de la ocultación de información por parte de los ayuntamientos respecto a los montes municipales y a la carencia de deslindes e insuficiencia de la guardería forestal, llegando a alcanzar muchas veces estas ocupaciones una importancia considerable, tanto en número como en extensión. Son múltiples las alusiones referentes a la amplitud que adquirió el fenómeno de las roturaciones arbitrarias en los montes valencianos ${ }^{6}$ en documentos concernientes al estado legal de éstos, y significativas las valoraciones relativas a la proporción del predio público que llegaron a ocupar.

El caso de los montes municipales de Altura es uno de los más representativos por lo que a invasión de terreno público se refiere, ya que, según el examen realizado de los mismos en 1903 con objeto de la formulación propuesta de declaración de utilidad pública a instancias de la alcaldía del término, «los tres montes forman una sola masa con tan escaso vuelo de pino halepensis que apenas habrá unas 80 hectáreas, hallándose la superficie restante cubierta de matas bajas, principalmente de coscoja y toda ella contiene numerosos enclavados, en su mayoria roturaciones arbitrarias que se calcula en un poco menos que la mitad de la cabidad total, los cuales abarcan particularmente casi toda la extensión del monte que se denomina Llanos de Cayetano» ${ }^{7}$. Igualmente significativos son otros ejemplos existentes en la provincia de Castellón, como el que refleja en 1954 el expediente del deslinde del monte de Castellfort denominado «Campillos» ${ }^{8}$ y el concerniente al monte denominado «Batalla» del término de Ahín ${ }^{9}$.

5 AUFC: Expediente del monte de utilidad pública n. ${ }^{\circ}$ 51; AUFV: Expediente del monte de utilidad pública n. ${ }^{\circ} 74$

6 Montiel Molina, C.: Montes de utilidad pública en la provincia de Alicante, Universidad de Alicante-Caja de Ahorros Provincial de Alicante, 1990, pp. 125-141.

7 AUFC: Expediente del monte de utilidad pública n. ${ }^{\circ} 60$.

8 AUFC: Expediente del monte de utilidad pública n. ${ }^{\circ} 20$.

9 AUFC: Expediente del monte de utilidad pública n. ${ }^{\circ} 7$. 
La capacidad productiva de los espacios forestales o la posibilidad de su transformación en terrenos de cultivo han sido los princi pales catalizadores de la máxima concentración de enclavados particulares en los montes públicos de la Comunidad Valenciana. Ello explica que los predios más afectados por esta problemática sean los situados en las proximidades de las principales zonas de producción agraria, los que cuentan con abundantes líneas de reunión de agua que permiten la formación de aterrazamientos a expensas del material acarreado, y las áreas donde el predominio de la facies silícea permite la formación de masas de alcornocal, cuya explotación ha supuesto para sus propietarios una importante fuente de ingresos.

En cualquier caso, las usurpaciones de dominio público por parte de los particulares colindantes y enclavados han sido el principal motivo de la disminución de superficie pública que se observa en los predios valencianos incluídos en los Catálogos con ocasión de la actualización de éstos. Numerosas son las referencias a este fenómeno que encontramos en las Memorias de Reconocimiento de los montes públicos elaboradas a fines del siglo pasado en cumplimiento de la Real Orden de 1877 que disponía la revisión del Catálogo de $1862^{10}$.

La ilegalidad de la mayor parte de las fincas enclavadas en los montes públicos valencianos queda evidenciada por la carencia de títulos de propiedad que repetidas veces han confesado los poseedores de las mismas y han denunciado los ingenieros forestales ${ }^{11}$. No obstante, fueron bastantes los particulares que lograron inscribir sus supuestos derechos en las Contadurías de Hipotecas y, más tarde, en los Registros de la Propiedad. El procedimiento más frecuente para obtener este tipo de reconocimiento ante la Ley fue el ya denunciado en 1856 por el Comisario de Montes de la provincia de Valencia ${ }^{12}$. Los particulares solían acceder a las suprimidas Contadurías con motivo de la celebración del acto de compra-venta de unos terrenos que el vendedor aseguraba haber recibido en herencia o haber adquirido por compra verbal; de esta manera adquiría el comprador un título

10 AUFC: Expedientes de los montes de utilidad pública n. ${ }^{\circ} 8,32,45$ y 47 ; AUFV: Expedientes de los montes de utilidad pública n. ${ }^{\circ} 16$ y 27.

11 AUFC: Expediente del monte de utilidad pública n. ${ }^{\circ}$ 63; AUFV: Expediente del monte de utilidad pública n. ${ }^{\circ} 16$.

12 Archivo de la Diputación Provincial de Valencia (A.D.P.V.): Sección de Fomento, Subsección de Montes, legajo 31. 
del que carecía el transmisor de la propiedad, dejando constancia de su existencia y «legalidad» en la Contaduría de Hipotecas del Partido ${ }^{13}$.

Los Registros de la Propiedad fueron asimismo testigos del afán de los poseedores de enclavados en montes públicos por adquirir una fórmula legal que avalara los derechos que afirmaban poseer sobre los terrenos ocupados. Son muchas las inscripciones que se efectuaron durante el último tercio del siglo pasado de fincas adquiridas por una tercera persona a título de compra-venta, cuyo poseedor aportaba únicamente la noticia verbal de su obtención por herencia o, a lo sumo, el testamento donde constaba la cesión de la misma, sin escritura, en cualquier caso, que justificara el dominio de los terrenos. A este origen responden algunos de los enclavados que existían en 1939 en el monte de Ballestar denominado «La Tenalla». Según la información facilitada por el Ayuntamiento de Ballestar, existían en el monte «Santo Domingo» ocho enclavados, situados en la partida de Solanes, Borrula y Forat Sur, y pertenecientes a vecinos de Fredes, La Cenia y Ballestar. Los dos primeros figuraban inscritos en el Registro de la Propiedad de Morella desde finales del siglo xIx; el tercero pertenecía a un particular en virtud de un documento de compraventa realizada el 7 de febrero de 1922 ante testigos, que se encontraba pendiente de inscripción en el Registro de la Propiedad; de los dos siguientes no existía documento alguno que justificara su titularidad, ya que habían sido adquiridos por compra verbal y por herencia paterna, respectivamente; el poseedor de la sexta finca únicamente podía fundamentar sus derechos en la anotación de la misma a su nombre en el Catastro; y las dos últimas habían sido, como la segunda y la tercera, adquiridas por título de compra-venta, del que se tomó razón en el Registro de la Propiedad ${ }^{14}$. Al mismo origen responde el predio conocido por el nombre de «La Gatellera» que el ICONA adquirió a un particular en 1975 con objeto de agregarlo al monte n. ${ }^{\circ} 3$ del Catálogo, situado en término de Vallibona y titulado «Santo Domingo» ${ }^{15}$.

13 AUFV: Expedientes de los montes de utilidad publica n. ${ }^{\circ} 16$ y 29.

14 AUFC: Expediente del monte de utilidad pública n. ${ }^{\circ} 2$.

15 El monte aparecía inscrito en el Registro de la Propiedad de Morella a favor de D. Fidel Quimerá Giner por título de herencia y mejora de su abuelo, al tomo 493, libro de Vallibona, folio 224, finca 2.479 (AUFC: Expediente del monte de utilidad pública n. ${ }^{\circ}$ ) 
El predio n. ${ }^{\circ} 26$ del Catálogo de Montes de Utilidad Pública de la Provincia de Alicante, denominado «Corrales del Marqués» y situado en término de Alicante, procede de la agrupación de tres fincas adquiridas en 1956 por el Patrimonio Forestal del Estado las cuales poseen el mismo origen que ofrecen las anteriormente señaladas ${ }^{16}$. Se trata de un monte de utilidad pública que fue enteramente poseido hasta 1956 por particulares, de forma fragmentada, en virtud de ocupaciones arbitrarias que adquirieron carácter legal desde el momento en que quedaron las fincas inscritas en la Contaduría de Hipotecas, y más tarde en el Registro de la Propiedad, en virtud de la compra efectuada por el titular de los terrenos o sus poseedores, quienes poseían como único justificante de sus derechos la escritura del testamento donde figuraba una propiedad de origen incierto.

Particular interés revisten, por otra parte, las inmatriculaciones ilegales practicadas a favor de un particular en el Registro de la Propiedad respecto a fincas enclavadas en montes incluidos en el Catálogo de los de utilidad pública como pertenencia estatal o municipal, que en algunos casos, figuraban incluso inscritos en el mismo Registro. Estas anomalías obedecen por lo general, además de al proceder erróneo de los registradores, por no efectuar la notificación que debieron cursar al Distrito Forestal antes de formalizar la inscripción solicitada por el particular en una zona próxima a terrenos forestales de dominio público, a la precariedad de muchas de las anotaciones relativas a montes catalogados debido al desconocimiento de la cabida real de éstos y al estado de indefinición de su perímetro por falta de deslindes.

Entre los casos que ilustran la situación descrita, destaca la inmatriculación de «una pieza de tierra en término de Cuatretonda, partida de Buixcarró, de cinco hanegadas, poco más o menos igual a cuarenta y una áreas, cincuenta y cinco centiáreas de extensión de tierra inculta con algunos olivos, lindante Norte Cantera de Buixcarró; Sur, propiedad particular del propio vendedor, Sr. Benavent, al Este y Oeste Antonio Benavent, conocido por Pau» a nombre de D. Felipe Tormo Huguet, vecino de Barcheta, en el Registro de la Propiedad de Albaida, al folio 196 del libro 322 de Cuatretonda. Esta

16 Registro de la Propiedad de Alicante, $n .^{\circ}$ 5: libro 673 de Alicante, folio 222, finca 13.200; l. 371 de Alicante, f. 133, fca. 6.493; l. 118 de Alicante, f. 104, fca. 8.338. 
parcela formaba parte del monte de utilidad pública n. ${ }^{\circ} 16$ del Catálogo de la Provincia de Valencia, cuyo deslinde había sido aprobado por Orden Ministerial de 20 de Julio de 1935, y que también fue inscrito en aquel Registro a favor del Ayuntamiento propietario al folio 111 del libro 15 de Cuatretonda (tomo 261 del Registro).

Si en el caso de Cuatretonda, fue el error cometido por el registrador la causa de la inscripción improcedente a favor de un particular de una finca perteneciente al monte de utilidad pública, otros casos, como el de «El Monte» del término de Antella, se producen como resultado de la vaguedad e imprecisión con que son a menudo inscritos los predios catalogados en el Registro de la Propiedad, al estar pendiente el deslinde y amojonamiento de los mismos. Esta es la razón de que en el Registro de la Propiedad de Alberique figurasen inmatriculados a nombre de particulares cinco fincas que, según el deslinde aprobado por Orden Ministerial de 16 de marzo de 1970, pertenecían al monte de utilidad pública ${ }^{17}$.

La presencia de fincas particulares enclavadas en montes de utilidad pública se ha visto favorecida, en consecuencia, por la falta de deslindes, así como por la insufiencia e ineficacia de la guardería. Son muchos los montes de la Comunidad Valenciana en donde los ingenieros atribuyen a estas circunstancias las dimensiones y multiplicidad que alcanzaron las antiguas parcelas dedicadas al cultivo ${ }^{18}$. La falta de deslindes y el desconocimiento del verdadero perímetro de los montes agravaba, además, el problema de la escasez de guardería, puesto que aquel estado de incertidumbre dificultaba extraordinariamente la tarea de los agentes forestales, al no saber éstos con seguridad dónde empezaba el dominio público y terminaba el privado ${ }^{19}$.

La mayor parte de los terrenos usurpados a los montes públicos por los particulares para ensanchar o multiplicar sus campos de cul-

17 Las fincas que la Orden Ministerial de 1970 declaró atribuidas al monte son las siguientes: a) a favor de D. Enrique Pous Mandria: t. 268, 1. 22, f. 236, fca. 2.739; b) a favor de D. Bernardo Jales Pla: t. 293, 1. 24, f. 59, fca. 2.812; c) a favor de D. José Roca Más: t. 268, 1. 22, f. 224, fca. 2.736; d) a favor de D. Elias Cantos Mompó: t. 68, l. 5, f. 85, fca. 852; e) a favor de D. ${ }^{a}$ Francisca Frigols Gómez: t. 144, 1. 13, f. 33, fca. 261 (AUFV: Expediente del monte de utilidad pública n. ${ }^{\circ}$ 124.)

18 Montiel Molina, C.: op. cit., 1990, pp. 133- 134.

19 Archivo de la Unidad Forestal de Alicante (AUFA): Expediente del monte de utilidad pública n. ${ }^{\circ} 44$. 
tivo aparecen en la actualidad abandonados por el uso agrario y en proceso de regeneración natural de la vegetación forestal, debido a la escasa rentabilidad que ofrecían aquellas tierras, lo que ha hecho desaconsejable el mantenimiento de los cultivos desde mediados del siglo actual, y, en algunos casos, incluso antes ${ }^{20}$.

Pese a la evidente inviabilidad productiva de aquellos espacios y a la manifiesta arbitrariedad de su dominio, son numerosas las disposiciones que han ofrecido a sus poseedores la posibilidad de legitimar la propiedad de los terrenos usurpados a los montes públicos a expensas de «la tolerancia política, el confusionismo legal o la turbulencia social de los períodos más conflictivos» ${ }^{21}$ en épocas en que el crecimiento demográfico y las dificultades económicas potenciaron la roturación de todo tipo de tierras ${ }^{22}$.

La intensidad que adquirió el fenómeno de las roturaciones arbitrarias a fines del siglo xvIII e inicios del xIx, y el afianzamiento de los campesinos en los terrenos ocupados, obligaron a los distintos gobiernos a definir un sistema que permitiera a los interesados legitimar los derechos adquiridos en una irregular situación fáctica. Esta fue la razón que animó la promulgación de la Real Orden de 24 de febrero de 1826, precursora de toda una serie de disposiciones que, a lo largo de la centuria pasada, reglamentaron el acceso a la propiedad plena de los poseedores de fincas usurpadas a montes públicos y favorecieron, en consecuencia, la proliferación de las mismas.

La Real Orden de 1826, que declaraba indultados «a los que hicieron rompimientos en la época Constitucional y á los que rompieron terrenos de montes antes de aquella época sin legítima facultad para ello», fue sucedida por el Decreto de 1837, la Ley de 6 de mayo de 1855 y toda la normativa que, durante la segunda mitad del siglo XIX, se ocupó de las roturaciones arbitrarias «unas veces con el ánimo fundamental de adaptarse a los preceptos de la legislación municipal -Reales Ordenes de 1862 y 1872- y, en otras ocasiones, con el obje-

20 Mangas Navas, J. M.: «Tierras marginales: Una vía para la reforma agraria», Agricultura y Sociedad, n. ${ }^{\circ}$ 25, abril-junio 1983, pp. 164-165.

21 Mangas Navas, J. M.: La propiedad de la tierra en España: los Patrimonios Rústicos (op. cit.), 1984, p. 256.

22 Mangas Navas, J. M.: El régimen comunal agrario de los Concejos de Castilla, Madrid, Ministerio de Agricultura, Pesca y Alimentación, 1981, pp. 238-242. 
tivo principal de fijar plazos y reglas para la provisión de títulos -Real Decreto de 1865 y Real Orden del mismo año- ...». En tiempos de la Restauración experimentó un nuevo impulso la tendencia legitimadora de roturaciones arbitrarias, cuya reglamentación fue contemplada en la Ley de Presupuestos de 1887. Y, ya en la centuria actual, distintas disposiciones han contemplado, hasta la fecha de aprobación de la Ley de Bases para la Reforma Agraria, la legitimación de unas tierras que, perteneciendo al patrimonio público, habían sido roturadas y transformadas» ${ }^{23}$.

Lo cierto es que, en la actualidad, los justificantes con que los particulares pueden acreditar la propiedad de los espacios que ocupan en el interior de predios públicos evidencian, por su inconsistencia jurídica, el origen arbitario de los derechos que aseguran poseer sobre estos terrenos. Esta problemática, común, por otra parte, a espacios forestales de otras regiones del territorio nacional, ha dado lugar a la reivindicación de la práctica totalidad de la extensión territorial de algunos montes, como sucedía a mediados del siglo en la Sierra del Segura ${ }^{24}$.

\section{Saneamiento del estado legal de los montes públicos}

La redención de los enclavados privados en montes de utilidad pública y la definición de los perímetros reales de éstos han sido los principales objetivos de la política de saneamiento del estado legal de los montes que, a mediados del siglo actual, emprendió el Patrimonio Forestal del Estado y más tarde han proseguido los organismos que le han sucedido en la gestión de los montes. Es compleja, no obstante, la problemática que entraña el esclarecimiento de las condiciones legales de los montes de utilidad pública, cuyos orígenes desconoce la Administración en la mayor parte de los casos y cuya titularidad es, en ocasiones, motivo de conflicto entre el Estado, los ayuntamientos y los particulares.

23 Mangas Navas, J. M.: op. cit., 1984, pp. 256- 262.

24 Araque Jiménez, E.: «Utilización del suelo y conflictividad social en la Sierra del Segura tras la Guerra Civil», Actas del III Coloquio de Geografía Agraria, Cáceres, 1985, pp. 47-53; Archivo de la Unidad Forestal de Valencia: Expedientes de los montes de utilidad pública n. ${ }^{\circ} 16$ y 56. 
El deslinde de los montes de utilidad pública.-La influencia que el deslinde de los montes públicos desempeña como factor limitativo $\mathrm{y}$ corrector de las usurpaciones efectuadas en estos espacios por los particulares es ciertamente decisiva. En este sentido, se pronunciaba de forma tajante el Ingeniero Jefe de la Provincia de Valencia en 1865 , al expresar que «donde haya una propiedad forestal de carácter público que no se halle deslindada, allí necesariamente hace falta esta operación para poner límite a las roturaciones o apropiaciones que de dicho predio forestal acostumbraban a hacer los dueños de las tierras colindantes» ${ }^{25}$.

La importancia que posee el deslinde de los montes públicos como operación previa a cualquier proyecto de ordenación forestal, e incluso a la propuesta de repoblaciones, ante la necesidad de definir y acotar la extensión del dominio público con anterioridad a la toma de decisiones sobre el mismo, y con objeto de garantizar el éxito de éstas, ha sido constantemente puesto de relieve por los ingenieros del ramo. Sin embargo, la carencia de recursos económicos y humanos ha impedido la verificación de estas operaciones en la mayor parte de los montes de la Comunidad Valenciana hasta fechas recientes, siendo muchos los que incluso hoy en día se encuentran sin deslindar y cuya extensión real desconoce, en consecuencia, la Administración Forestal.

Con frecuencia, la necesidad del deslinde de los montes catalogados se ha justificado a partir de la conveniencia de llevar a cabo tareas de ordenación, mejora y repoblación forestal en los mismos. Este es el caso, entre otros, del monte n. ${ }^{\circ} 52$ del Catálogo de la Provincia de Castellón, perteneciente a los propios de Chovar, para cuya explotación racional planteó en 1967 el Distrito de aquella provincia la formación de un grupo junto con los otros dos montes del mismo término, incluidos en el Catálogo con los números 51 y 53; «de ahí el interés en que esta mejora sea precedida de la defensa de la propiedad, aparte de los beneficios que en sí reporta y el interés que por él mismo tiene la ejecución de un deslinde» ${ }^{26}$.

25 AUFV: Expediente del monte de utilidad pública n. ${ }^{\circ} 29$.

26 Memoria prelimar al deslinde del monte «Bellota», del término de Chovar (AUFC: Expediente del monte de utilidad pública n. ${ }^{\circ}$ 52). 
También el deslinde del monte de Jarafuel denominado «Muela de Juey» fue acordado por la Dirección General del ramo en 1870 a propuesta de la Comisión de Repoblación de la Cuenca del Júcar, que señaló la necesidad de verificar el deslinde de aquel monte de propios para dar comienzo a los trabajos definitivos de repoblación y corrección hidrológico-forestal de aquel sector de la cuenca ${ }^{27}$.

Sin embargo, y pese a su enorme trascendencia, los trabajos de apeo y deslinde de los montes públicos valencianos han sido tradicionalmente escasos, tardíos e insuficientes. Razones de presupuesto y de infradotación de personal han sido, por regla general, las causas que han justificado esta carencia, cuyas repercusiones se han dejado notar en el gran número de abusos cometidos en los predios públicos al amparo del confusionismo legal. Tal fue la resignación de los ingenieros, ante la evidente imposibilidad de practicar el deslinde de los montes dependientes de la Administración del ramo, que dejaron de proponer la necesidad de llevar a cabo estos trabajos en sus respectivos Distritos, a pesar de seguir insistiendo en la importancia y conveniencia de los mismos ${ }^{28}$.

Los montes que con mayor urgencia precisan la verificación de los trabajos de apeo y deslinde son aquellos que cuentan con zonas que poseen un valor económico superior al derivado de su vocación forestal, es decir, aquellos espacios potencialmente transformables en zonas agrícolas de regadío o que ofrecen la posibilidad de su utilización para fines turísticos. Ambos factores confluyen en montes situados en municipios de primera y segunda línea de costa, tales como el denominado «La Comediana», del término de Albalat de Taronchers ${ }^{29}$. En otros, como «Las Ródanas», de los propios de Villamarchante, la urgencia del deslinde se justifica por el gran número de transformaciones de fincas de secano en regadío para dedicarlas al cultivo de naranjos, siendo esta operación necesaria para evitar posibles apropiaciones indebidas de los propietarios colindantes con miras a incrementar las superficies susceptibles de transformación ${ }^{30}$.

\footnotetext{
27 AUFV: Expediente del monte de utilidad pública n. ${ }^{\circ} 29$.

28 Escrito del Ingeniero Jefe del Distrito Forestal de Castellón, fechado el día 19 de octubre de 1868 (AUFC: Expediente del monte de utilidad pública n. ${ }^{\circ}$ 7).

29 AUFV: Expediente del monte de utilidad pública n. ${ }^{\circ} 100$.

30 AUFV: Expediente del monte de utilidad pública n. ${ }^{\circ} 91$.
} 
El monte de Estivella denominado «El Garbí» fue, en cambio, objeto de deslinde en 1977 ante la posibilidad de que se cometieran intrusiones provocadas por la apetencia que suscitaba aquella zona para la construcción de chalets ${ }^{31}$.

Los problemas derivados de la ocupación indebida de los terrenos catalogados para fines agrarios y urbanísticos han dificultado, en muchos casos, la ejecución de los deslindes, paralizando en algunas ocasiones los trabajos, o provocando un permanente estado de provisionalidad o tramitación, al ser repetidas veces recurrido el resultado de las operaciones practicadas, dando lugar a numerosos replanteos parciales en la colindancia con propiedades particulares conflictivas. Paradigmático es, en este sentido, el caso del monte del término de Alcira denominado «Las Agujas».

El saneamiento del estado legal de los montes públicos es, en consecuencia, uno de los problemas más acuciantes que afectan al espacio forestal valenciano, por ser, en definitiva, el fundamento en que se apoya el éxito de la aplicación de los principios de la política forestal. La escasa atención que, entre la opinión pública, despierta este grave problema que afecta a los montes valencianos, debido al acaparamiento de la atención por parte de otros asuntos de carácter sensacionalista, como son los incendios y las repoblaciones forestales, no favorece la superación del estadio de desconocimiento y abandono de los aspectos legales en que se encuentran buena parte de los predios públicos valencianos.

Es precisamente la incertidumbre que impera en torno a los perímetros y cabidas reales de los montes catalogados, la razón que impide ofrecer unas cifras seguras acerca de la superficie total de utilidad pública de cada provincia y sobre la extensión y el número de los enclavados particulares. Son todavía muchos los montes del Catálogo que se encuentran sin deslindar y cuyos límites y cabida son inciertos, aun para los propios ingenieros forestales, lo que continúa amparando las usurpaciones de dominio, sobre todo en el caso de predios que ni siquiera han sido inmatriculados en el Registro de la Propiedad.

${ }^{31}$ AUFV: Expediente del monte de utilidad pública n. ${ }^{\circ} 102$.

$$
-506-
$$


La inscripción de los montes catalogados en los Registros de la Propiedad.-Abundan, efectivamente, en la Comunidad Valenciana, los montes de utilidad pública que, a pesar de la obligatoriedad que establecen la Ley y el Reglamento de Montes vigentes respecto a la inscripción en el Registro de la Propiedad de los predios catalogados, no figuran inmatriculados en el mismo ${ }^{32}$. En algunos casos ésta deficiencia obedece al hecho de no haber sido reinscrito el monte tras la destrucción de los libros registrales durante la Guerra Civil, ya que, pese a no figurar actualmente inmatriculados, tenemos constancia de la anotación de dominio efectuada durante la segunda mitad del siglo pasado por parte del Estado, con intereses desamortizadores, o a favor de los Ayuntamientos en el marco de una política de defensa de los bienes municipales ${ }^{33}$.

Destaca, entre los montes que no han sido inscritos en el Registro de la Propiedad, el notorio predominio de aquellos que pertenecen a los municipios, llegando a producirse el caso de aparecer únicamente inmatriculados los montes pertenecientes al Estado en un determinado municipio, y encontrarse ausentes todos los predios municipales radicados en el mismo término, tal y como ocurre con respecto a los montes de Ahín, Crevillente, Jávea, Jijona, Novelda y Serra, entre otros.

De todos modos la desidia ante la inscripción de los montes en el Registro no ha sido rasgo exclusivo de los ayuntamientos, ya que tampoco el Estado ha mostrado, por lo común, hasta fechas recientes, gran atención a la inmatriculación de los predios catalogados. Salvo en casos de manifiesto interés por la enajenación del monte en pública subasta, que obligaba al Estado a efectuar la anotación de la finca en el Registro de la Propiedad para que el adquiriente pudiera inscribir a su favor el dominio de la misma por título de compra-venta, las inscripciones se demoraron hasta mediados del siglo actual, en que el Patrimonio Forestal del Estado dio un impulso notorio a las inmatriculaciones de montes estatales. Además, existen también

32 Artículo 11 de la Ley de Montes y artículo 69 de su Reglamento.

33 Montiel Molina, C.: «La titularidad de los montes de utilidad pública valencianos a través de los Registros de la Propiedad», Actas del VI Coloquio de Geografía Rural, Departamento de Geografía de la Universidad Autónoma de Madrid, 1991, pp. 149-159. 
ejemplos en la Comunidad Valenciana de municipios como el de Elche, donde son los montes estatales aquellos que se encuentran ausentes de los libros registrales, figurando únicamente inscritos los que pertenecen al municipio, como consecuencia del interés de los pueblos valencianos por salvaguardar la titularidad de los montes municipales.

Merece la pena destacar, por su excepcionalidad, el caso de los montes de la provincia de Alicante que aparecen inmatriculados a nombre de un particular en el Registro de la Propiedad, pese a figurar incluidos en el Catálogo de los Utilidad Pública como montes de pertenencia estatal. Se trata del monte n. 47 del Catálogo de la Provincia de Alicante, denominado "Umbría y Mariola» situado en término de Agres, y del «Cabezo de la Sal», que consta con el n. ${ }^{\circ} 82$ y radica en el término de Pinoso.

El primero accedió al Registro de la Propiedad de Concentaina el 22 de septiembre de 1893 como finca perteneciente al Estado en virtud de la Ley de Desamortización, constando en la segunda anotación de dicha finca la adjudicación en pública subasta a un vecino del mismo término de Agres.

En la misma fecha en que fueron realizadas las dos primeras anotaciones quedó hipotecado el monte, según tercera y última anotación, a favor de Hacienda, para responder de la parte del precio aplazada, figurando entre las cláusulas de la hipoteca que «si la finca fuese declarada en quiebra por falta de pago de cualquiera de los plazos quedan desde luego anulados y sin ningún valor ni efecto las hipotecas que sobre la misma haya podido constituir el comprador a favor de tercero» ${ }^{34}$.

El comprador no hizo efectivo ninguno de los nueve plazos adeudados, o al menos no consta que los pagase -según informe remitido el 25 de febrero de 1991 por el Director Territorial de Agricultura y Pesca en Alicante al Director General de Política Forestal Pesquera-, razón por la cual el Estado -y en su nombre la Generalidad Valenciana, actualmente- se atribuye la propiedad de «Umbría o Mariola», por haber continuado «desde tiempo inmemorial» en su posesión y haberlo incluido regularmente en los planes anuales de aprovecha-

${ }^{34}$ Registro de la Propiedad de Cocentaina: t. 533, f. 190. 
miento ${ }^{35}$. Sin embargo, y dado que según la última anotación del monte en el Registro de la Propiedad, éste pertenece a un particular, cuando el Estado intentó inmatricular a su favor la titularidad de la finca, mediante certificación expedida por el Ingeniero Jefe del Distrito, el Registrador denegó la inscripción solicitada por contradecirse con la ya existente.

Parecido es el caso del «Cabezo de la Sal» de Pinoso, que fue inmatriculado en el Registro de la Propiedad de Monóvar, como traspaso de la inscripción existente en el folio 146 del libro $10^{\circ}$ de fincas rústicas de Pinoso perteneciente al antiguo Registro o Contaduría de Hipotecas ${ }^{36}$. Dicho monte quedó hipotecado a favor del Estado hasta que el comprador satisfaciera los nueve plazos restantes del importe, quedando cancelada la hipoteca el día 6 de junio de 1877, según la inscripción $15^{\circ}$ de la finca, por haber sido abonado el importe total de la venta. En 1864, y tras haber sido efectuados el deslinde y el amojonamiento del monte, el comprador vendió quince dieciseisavas partes del mismo, en común y proindiviso, inscribiendo los nuevos propietarios su título de dominio en el Registro de la Propiedad. Diez años después, varios de aquellos copropietarios o sus herederos cedieron la titularidad y los derechos de sus respectivas partes a favor de D. Ricardo San Miguel Bustamante, quien inscribió su título de dominio sobre $9 / 16$ y $3 / 5$ de 1/6 partes del monte.

Continuó el mencionado cedatario adquiriendo divisiones del monte, y constituyendo diversas hipotecas sobre las mismas, hasta que en 1880, viendo la dificultad de recuperar los derechos hipotecados a D. Eusebio Caja y Martinez y a la Sociedad Pastor, Abat y Compañía, decidió traspasar sus derechos al retro a otra persona que contase con medios para, en su día, retraer lo enajenado, cediendo dichos derechos a D. Pedro Pagan y Ayuso por la cantidad de 16.250 pts. Desapareció así el Sr. San Miguel Bustamante de las anotaciones de propiedad del «Cabezo de la Sal» en 1880, quedando en su lugar D. Patricio Pastor - uno de los tres socios de la mencionada Sociedad, disuelta en 1880- y D. Eusebio Caja, como propietarios de la mayor parte del monte.

35 AUFA: Expediente del monte de utilidad pública $\mathrm{n}^{\circ} 47$.

36 Registro de la Propiedad de Monóvar: t. 33, 1. 10 de Pinoso, f. 186, fca. 894. 
Sin embargo, el Delegado de Hacienda de Alicante dispuso, por decreto de 19 de noviembre de 1895, que la Administración Forestal quedara encargada de la gestión y explotación o aprovechamiento del «Cabezo de la Sal» de Pinoso «que fue de D. Ricardo San Miguel, interin no se acuerde la venta del mismo si procediere, depurado que sea el derecho que pudiese asistir a la Hacienda por el procedimiento que a dicho fin se está incoando». Así fue como, según oficio dirigido por el ingeniero de la Sección al Ingeniero Jefe del Distrito el día 30 de aquel mes y año, fue tomada posesión del monte, conforme a lo ordenado, asistiendo al acto de entrega el alcalde del término y el administrador del monte ${ }^{37}$, no obstante lo cual continuó figurando éste a nombre de particulares en el Registro, siendo puntualmente anotadas las sucesivas trasmisiones de propiedad que, por título de herencia y compra-venta, iban produciéndose. Son así un total de dieciseis las inscripciones que se practicaron con posterioridad al supuesto embargo de la finca a D. Ricardo San Miguel, quien, por otra parte, ya no figuraba como titular de la misma, según las anotaciones del Registro de la Propiedad, en la fecha del embargo.

En el año 1896 la Administración de Hacienda incoó un expediente de incautación y venta por quiebra del monte de Pinoso, resultando que el 14 de agosto llevó a efecto la incautación de la finca el Alcalde del término en nombre del Estado y a tenor de lo dispuesto por la Administración de Bienes y Derechos del Estado. Sin embargo el monte no llegó a ser enajenado de nuevo, permaneciendo bajo la administración del Distrito hasta que, en 1985, al tratarse de inscribir los derechos del Estado como titular de la finca en el Registro de la Propiedad, fue denegada su petición, por encontrarse ya inscrita la misma finca a nombre de particulares. Así consta en la anotación preventiva $\mathrm{H}$ del monte, inscrita el 30 de enero de 1985 y cancelada en 1986.

Se convierten así los ejemplos de «Umbría o Mariola» y «Cabezo de la Sal» en prueba de la divergencia que, en ocasiones, existe entre el Registro de la Propiedad y el Catálogo de Montes de Utilidad Públi-

${ }_{37}$ AUFA: Expediente del monte de utilidad pública $n .^{\circ} 82$.

$$
-510-
$$


ca, no sólo por el ilegal proceder de los particulares al efectuar «inscripciones desbordadas e invasoras» ${ }^{38}$ al amparo de la desidia de la Administración, que ha retardado indefinidamente la inscripción de los montes catalogados en el Registro de la Propiedad, sino también por el confusionismo que existe en torno al estado legal de estos predios, objeto de múltiples conflictos de titularidad entre la Administración Pública y los particulares ${ }^{39}$.

La politica de adquisiones de terreno forestal.-Entre los objetivos con que fue creado el Patrimonio Forestal del Estado figura la restauración, conservación e incremento de la riqueza forestal pública, al servicio de lo cual ha venido practicando la Administración, durante la segunda mitad del siglo actual, una dinámica política de adquisiciones de tierras con vocación forestal en la región valenciana. La propia Ley Forestal de la Comunidad Valenciana, recientemente aprobada ${ }^{40}$, señala, entre las formas de actuación previstas para el cumplimiento de los objetivos de la política forestal definida, la «defensa de la propiedad forestal de utilidad y dominios públicos» y establece el propósito de incrementar la propiedad forestal patrimonial de la Generalidad Valenciana ${ }^{41}$

En su mayor parte, las adquisiciones de fincas de monte han estado relacionadas con los propósitos de protección que orientaban los trabajos de corrección hidrológico-forestal tendentes a la regulación de cuencas de recepción de embalses o de cursos torrenciales y a la defensa de las zonas regables. Por tanto, un buen número de las compras efectuadas por el Patrimonio Forestal del Estado, y más tarde por el ICONA, se encuentran en las zonas de urgente repoblación y en los perímetros de repoblación obligatorios, existiendo, como ha señalado Gómez Mendoza, una clara relación entre la política de

\footnotetext{
${ }^{38}$ Alcalá Zamora, N.: «Inscripción de los montes públicos en el Registro de la Propiedad», Revista de Montes, 1926, n..$^{\circ} 1.111$, pp. 404-405.

39 Montiel Molina, C.: op. cit., 1990, pp. 144-146.

40 Ley 3/1993 de diciembre, de la Generalidad Valenciana, Forestal de la Comunidad Valenciana (DOGV, n. ${ }^{\circ}$ 2.168, de 21 de diciembre de 1993).

41 Art. 6. ${ }^{\circ}$ c) y e), y art. 39 de la Ley $3 / 1993$ de diciembre, de la Generalidad Valenciana, Forestal de la Comunidad Valenciana.
} 
compras-consorcios-repoblaciones, enlazados estos aspectos por un estrecho vínculo de causa-efecto ${ }^{42}$.

El Valle de Albaida ha sido una de las comarcas, junto con el Maestrazgo castellonense, más afectadas por la política de adquisiciones estatales desde que, por Real Decreto de 8 de febrero de 1907, fueran declarados de utilidad pública los trabajos hidrológico-forestales proyectados en la Sección $1^{a}$ de la Cuenca del Río Albaida, denominada «Valle de Albaida», por la Segunda División Hidrológica-Forestal. En virtud de aquella disposición fueron expropiados a ayuntamientos y particulares, durante la primera mitad de siglo, la mayor parte de los montes estatales de esta comarca que figuran en la actualidad incluidos en el Catálogo de los de utilidad pública, según se desprende de las anotaciones de los mismos efectuadas en el Registro de la Propiedad del partido. Este es el origen, por tanto, de «La Sierra» de Adzaneta de Albaida» ${ }^{43}$, «Cova Alta y Plá de Euroela» de Albaida ${ }^{44}$, «Ermitario de San Vicente» y «La Sierra» de Agullent ${ }^{45}$, «La Sierra» de Benisoda» ${ }^{46}$, «La Sierra» de Bufalit ${ }^{47}$, «La Sierra de Carricola» ${ }^{48}$, «La Sierra» de Otos ${ }^{49} \mathrm{y}$ «La Sierra» de Palomar ${ }^{50}$.

$\mathrm{Al}$ mismo fin sirvieron otras fincas que el Patrimonio Forestal del Estado adquirió por traspaso del Ministerio de Hacienda, quien a su vez las había expropiado a sus propietarios por débitos de contribución. Este fue el caso de montes como el radicado en el término de Jalance y conocido como «Pico de la Muela», integrado por dos fincas que fueron expropiadas por Hacienda y a las que más tarde se agregó otras adquiridas por el Patrimonio Forestal del Estado al Ayuntamiento y a 194 vecinos propietarios del término ${ }^{51}$.

${ }^{42}$ Gómez Mendoza, J. y Mata Olmo, R.: «Actuaciones forestales públicas desde 1940: Objetivos, criterios y resultados», en Gil Olcina, A.-Morales Gil, A. (ed.): Medio siglo de cambios agrarios en España, Alicante, Instituto de Estudios Juan Gil-Albert, 1993, pp. 151-190.

${ }_{43}$ Registro de la Propiedad de Albaida: t. 86, 1. 4 de Adzaneta de Albaida, f. 136, fca. 648 .

${ }_{44}$ Registro de la Propiedad de Albaida: t. 127, 1. 16 de Albaida, f. 232, fca. 2.145.

45 Registro de la Propiedad de Onteniente: t. 174, 1. 12 de Agullent, f. 210, fca. 1.355 .

46 Registro de la Propiedad de Albaida: t. 237, 1. 3 de Benisoda, f. 105, fca. 346.

47 Registro de la Propiedad de Albaida: t. 71, 1. 2 de Bufalit, f. 178, fca. 284.

48 Registro de la Propiedad de Albaida: t. 279, 1. 5 de Carrícola, f. 15, fca. 548.

49 Registro de la Propiedad de Albaida: t. 112, 1. 4 de Otos, f. 73, fca. 524.

50 Registro de la Propiedad de Albaida: t. 105, l. 4 de Palomar, f. 14, fca. 520.

51 AUFV: Expediente del monte de utilidad pública n. ${ }^{\circ} 134$. 
No menos importante es la adquisición de fincas forestales en comarcas deprimidas, como la del Maestrazgo, que sufren un abandono progresivo de tierras agrícolas marginales, procedentes en su mayoría de terrenos usurpados al monte público en tiempos de crecimiento demográfico o de dificultades económicas. La pérdida de interés de estas fincas para sus propietarios y el bajo precio del suelo en estas comarcas, han facilitado al Patrimonio Forestal del Estado, y más tarde al ICONA, la tarea de recuperación de terrenos de vocación forestal que estaban siendo, por otra parte, objeto de regeneración natural tras su abandono.

La práctica totalidad de los montes adquiridos por el Estado en la provincia de Castellón se concentran, por tanto, en la comarca del Maestrazgo, y están formados por la agrupación de múltiples fincas de perímetros irregulares y extensión reducida que ha ido paulatinamente concentrando la Administración Forestal hasta conformar varios predios que permitieran llevar a cabo tareas de gestión y ordenación racionales. Este es el origen de la mayor parte de los montes castellonenses recientemente incluidos en el Catálogo a nombre del Estado o de la Generalidad Valenciana.

La actitud de la Administración Forestal ante las zonas valencianas de cultivo marginal o áreas deprimidas que sufren un éxodo masivo como consecuencia del condicionamiento socioeconómico, queda claramente definida en la Memoria de Propuesta para la declaración de utilidad pública e inclusión en el Catálogo del monte "Santo Domingo, Parcela Más de Boix II», redactada por el Ingeniero Jefe del Distrito Forestal de Castellón en 1975: «...Posteriormente a la adquisión del monte "Mas de Cocons», en el término municipal de Vallibona, intentó el ICONA continuar comprando terrenos en esta cuenca, ya que por sus características de abandono de los pueblos próximos, dificultad de comunicaciones y gran extensión montañosa, entendemos que sea relativamente fácil que vayan cayendo muchas fincas en manos del Estado...» 52.

El monte castellonense de «Mas de Ascle», radicado en los términos municipales de Alcalá de Chivert, Santa Magdalena de Pulpis y

52 AUFC: Expediente del monte de utilidad pública n. ${ }^{\circ} 3$.

$$
-513-
$$


Cuevas de Vinromá, es un extraordinario ejemplo de formación de una «unidad de gestión y explotación forestal» a partir de compras y ocupaciones sucesivas, ya que, en su totalidad, está integrado por pequeñas parcelas adquiridas a particulares ${ }^{53}$. También el monte denominado «Tristany y la Mina», situado en los términos de Segorbe y Gátova, es el resultado de distintas adquisiciones verificadas a partir de 1961, relacionadas, en este caso, con la situación de la zona en el interior del perímetro de repoblación obligatoria aprobado por Decreto de 15 de julio de 1955. A la finca que da nombre al predio fueron agrupadas dos más del término de Segorbe -«Cerro del Sastre»y «Pico del Aguila»- y dos en Gátova - «La Moratilla» y «Peña Blanca»- formando, en su conjunto, la finca matriz a la que posteriormente se agregaron otras parcelas adquiridas por compra o en virtud de renuncia a favor del Patrimonio Forestal del Estado realizada por sus antiguos propietarios, cediéndolas a la Administración para la ejecución de trabajos de repoblación forestal ${ }^{54}$.

Este es asimismo el origen que presentan dos predios castellonenses propuestos para su inclusión en el Catálogo bajo las denominaciones de «Umbrías de Benifasar» y «Mas del Rey». El primero, situado en el término municipal de Ballestar, anexionado a la Puebla de Benifasar, fue obtenido por sucesivas agrupaciones de parcelas colindantes y próximas entre sí, y está formado por un total de once fincas que suman una superficie de 593,35 hectáreas. El segundo, radicado en el término de Chert, está integrado por el mismo número de fincas, que comprenden una extensión de 499,5960. Ambos figuran actualmente en el Elenco de Montes de la provincia de Castellón con las claves CS-1.027 y CS-1.023, respectivamente.

Ha sido igualmente frecuente la adquisición de fincas enclavadas o colindantes con montes de utilidad pública con objeto de sanear el estado legal de estos predios, regularizar su perímetro y ampliar su cabida. Entre los ejemplos más representativos se encuentra el monte n. $^{\circ} 3$ del Catálogo de la Provincia de Castellón, sito en el término de Vallibona y conocido bajo la denominación de «Santo Domingo». Este monte, en cuya posesión se encontraba el Estado a mediados

53 AUFC: Expediente del monte de utilidad pública n. ${ }^{\circ} 99$.

54 AUFC: Expediente del monte de utilidad pública n. ${ }^{\circ} 88$. 
del siglo pasado por incautación a comunidades religiosas en virtud de las disposiciones desamortizadoras, ha sido objeto de sucesivas anexiones, a partir de 1973, de parcelas ofertadas en venta al Estado por sus propietarios, muchas de las cuales no contaban con escritura de dominio ni habían sido siquiera inscritas en el Registro de la Propiedad.

Similar al caso de «Santo Domingo» es el de «La Tenalla», radicado en el término de Ballestar y Puebla de Benifasar, e incluido en el Catálogo de Montes de Utilidad Pública con el n. ${ }^{\circ} 2$. A este monte, procedente de la incautación llevada a cabo por el Estado al Monasterio de Santa María de Benifasar, han sido agregadas varias fincas adquiridas por el Patrimonio Forestal del Estado y por el ICONA. No obstante, la causa de las adquisiciones ha sido en este caso diferente, ya que el propósito perseguido en realidad era la realización de trabajos de conservación del suelo, por encontrarse aquellas parcelas situadas en la cuenca del Pantano de Ulldecona y formar parte del Perímetro de Repoblación Obligatoria declarado por Decreto de 15 de julio de 1955 .

Llama la atención el modo en que el Estado ha llevado a cabo la mayor parte de las citadas adquisiciones, adaptándose a la complejidad que presenta la estructura de la propiedad del espacio forestal valenciano, integrado por numerosas fincas particulares de contorno irregular y reducida extensión, cuyos poseedores carecen a menudo de títulos de dominio o cualquier otro justificante de propiedad. Estas circunstancias, que impedían a la Administración Forestal efectuar la compra de unos terrenos que no reunían las condiciones establecidas por la Ley, fue normalmente superada mediante la intervención de un intermediario, conocedor de la realidad comarcal, que adquiría por encargo del Patrimonio Forestal del Estado o del ICONA las fincas a sus poseedores y, tras sanear el estado legal de las mismas, inscribirlas en el Registro de la Propiedad y agruparlas, las ofertaba en venta al Patrimonio Forestal del Estado.

Así se explica que figuren inscritas en los Registros de la Propiedad de la Comunidad Valenciana a nombre del mismo vendedor un buen número de montes adquiridos, en distintos términos municipales de la región, por el Patrimonio Forestal del Estado o por el ICO- 


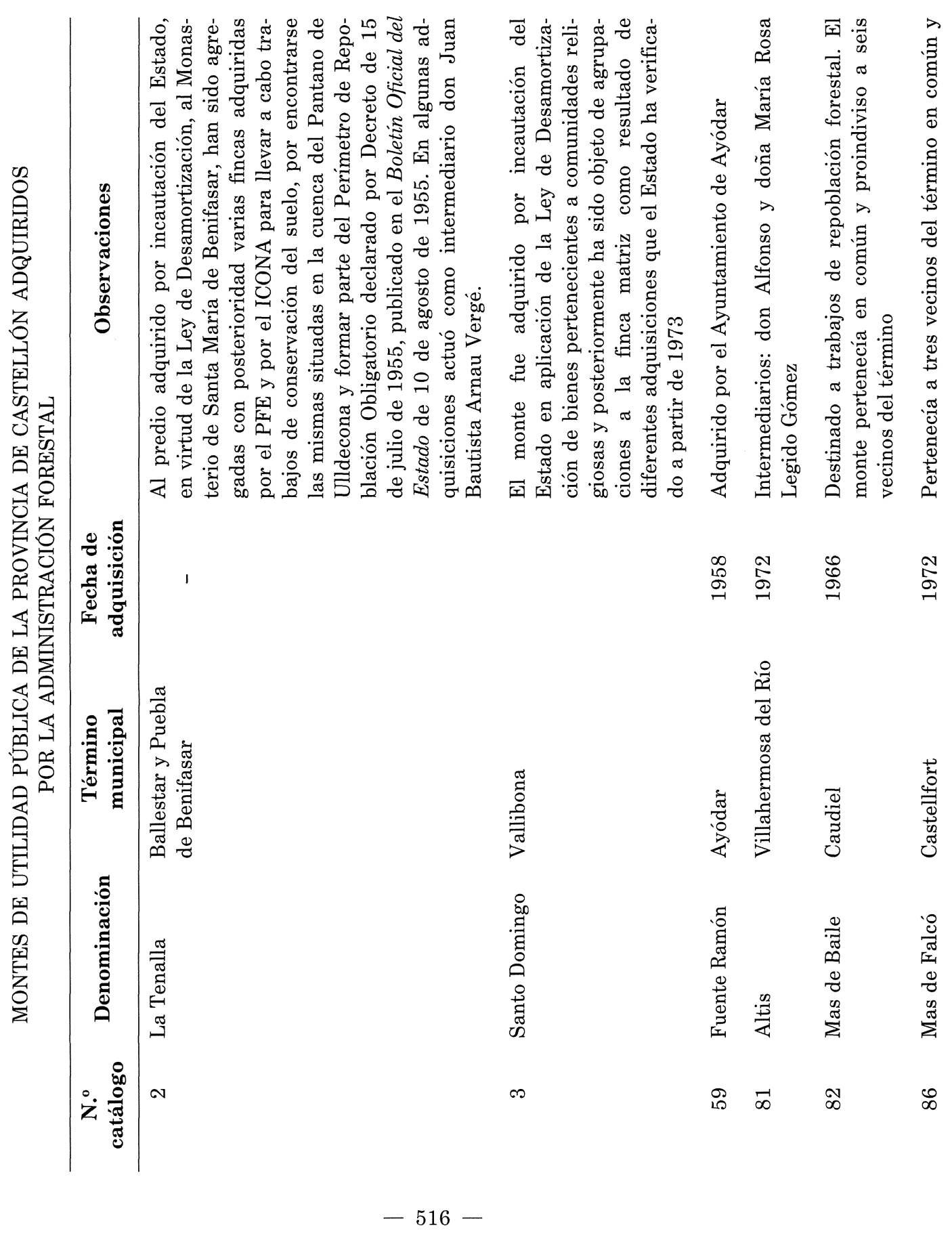



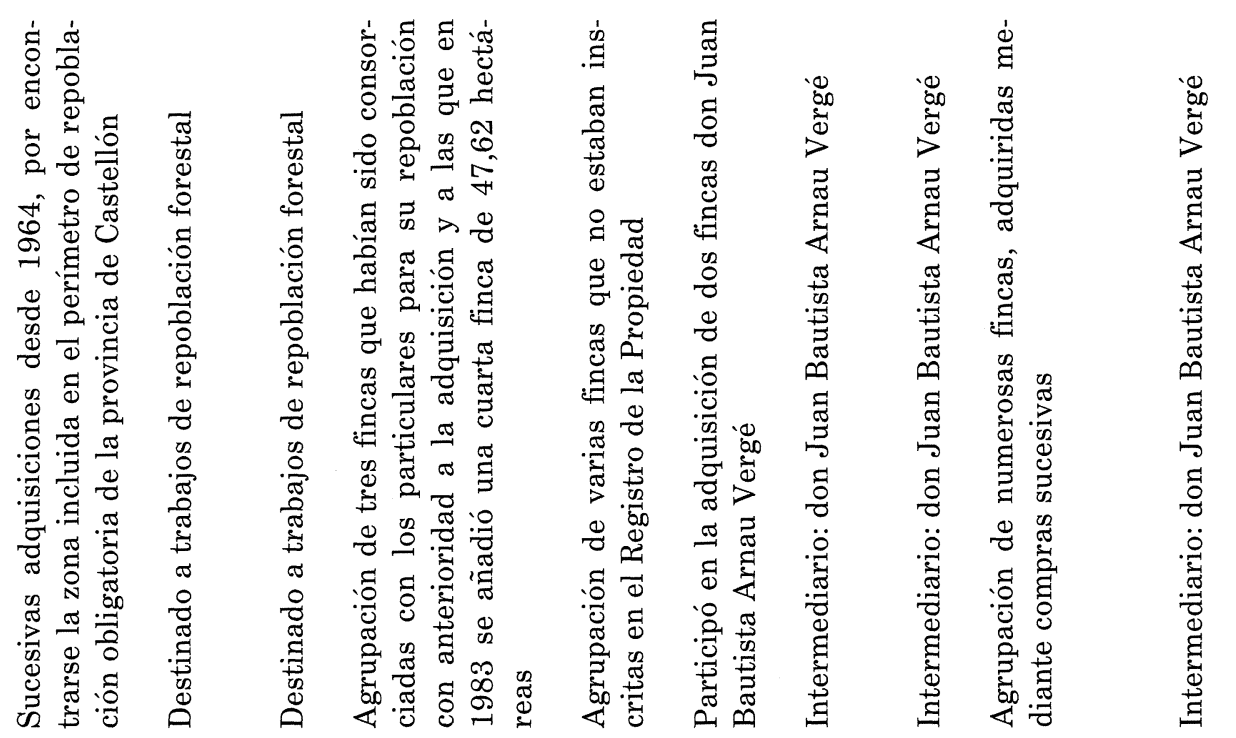

$\begin{array}{lll}\text { g } & 8 & \circ \\ \mathscr{2} & \stackrel{5}{-1}\end{array}$

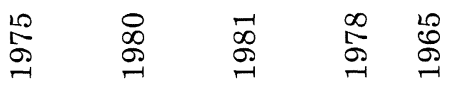

$\stackrel{\infty}{\circ}$

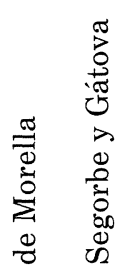

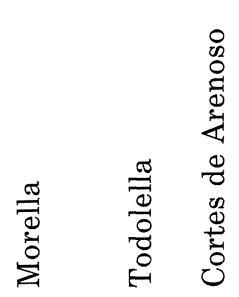

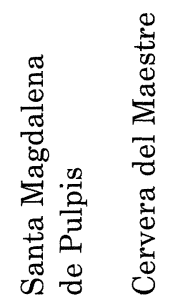

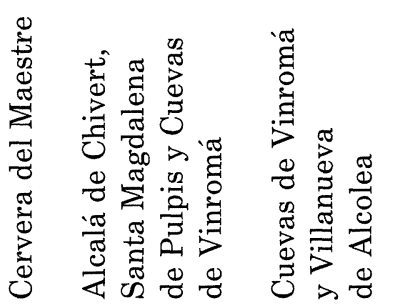

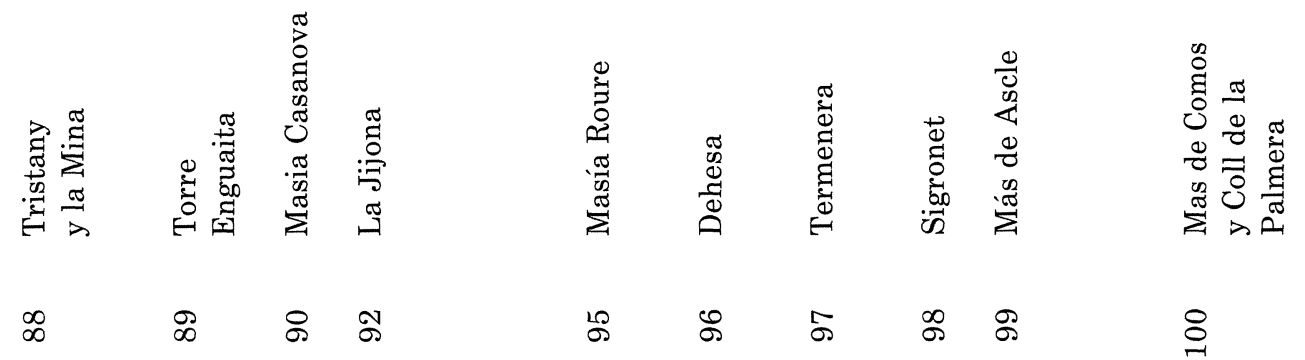




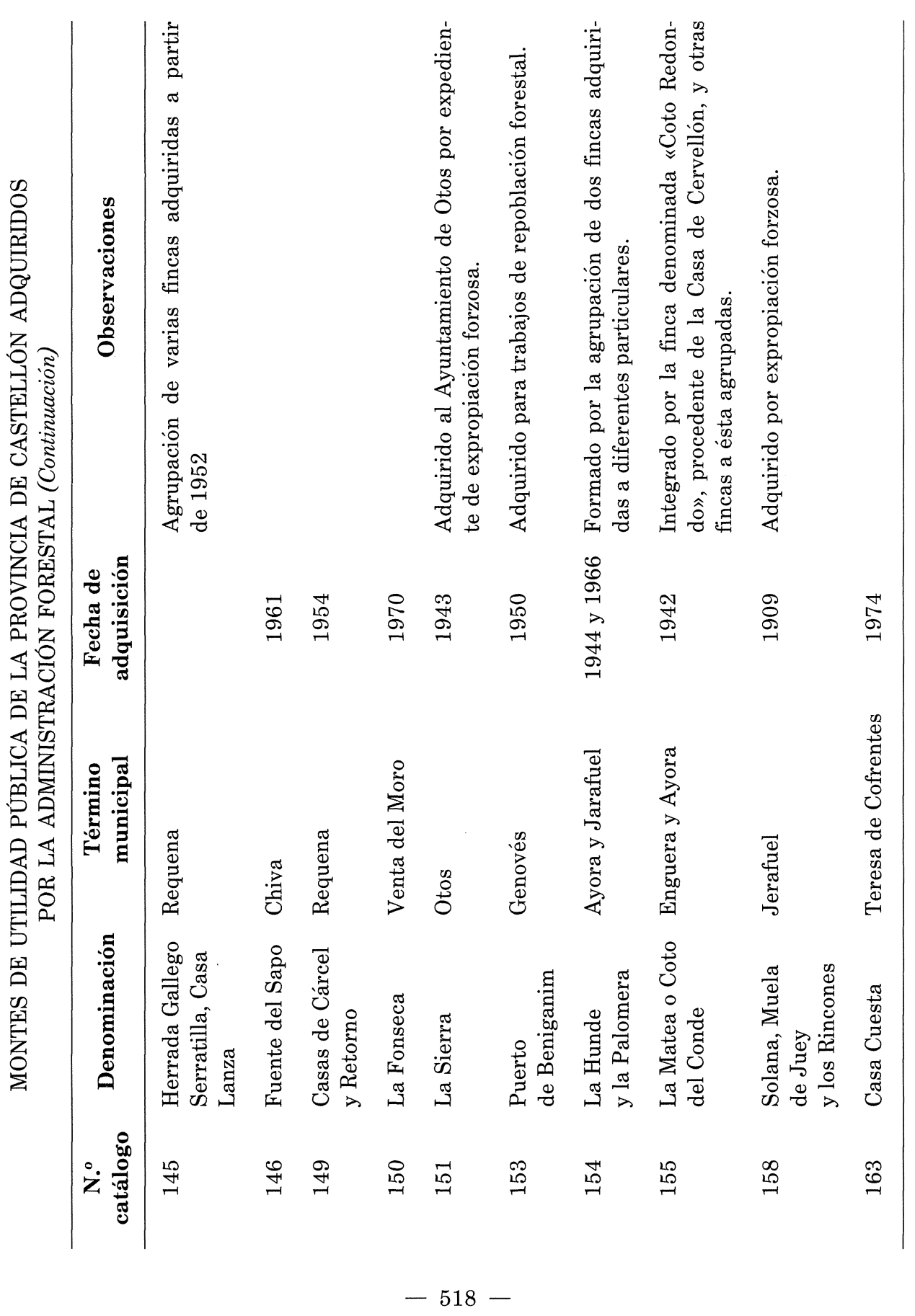


NA. Es, en este sentido, representativa la figura de un vendedor a quien, según las inscripciones practicadas en los Registros de la Propiedad, adquirió el ICONA la «Dehesa» de San Mateo, «Termenara» en Santa Magdalena de Pulpis, «Sigronet» en Cervera del Mestre, «Mas de Comos y Coll de la Palmera» en Cuevas de Vinromá y Villanueva de Alcolea, y algunas de las fincas anexionadas al monte «La Tenalla» de Ballestar y Puebla de Benifasar. Queda encubierta, de esta manera, la existencia de una pluralidad de propietarios extraordinariamente variada y compleja tras las adquisiones de terreno efectuadas por la Administración Forestal.

Otras veces el ICONA ha recurrido a la expropiación forzosa para adquirir fincas ofertadas por particulares que carecían de títulos de propiedad y con quienes, por tanto, no podían firmar un contrato de compra-venta. Este es el sistema utilizado a menudo para adquirir terrenos situados en áreas de especial interés por la frecuencia de los incendios forestales o por su dedicación a tareas de repoblación forestal. De esta forma quedaba atendida la oferta formulada por el particular y, al mismo tiempo, satisfecho el interés por el incremento patrimonial de la Administración.

La mayor parte de las fincas adquiridas por el ICONA en la Comunidad Valenciana durante los años en que este organismo estuvo encargado de la gestión de los montes de la región, fueron transferidas a la Generalidad Valenciana a tenor de lo dispuesto en el Decreto 2.365/1984 de 8 de febrero, el día 1 de enero de 1985, de manera que en la actualidad están sujetas a la Administración de la Generalidad Valenciana a través de la Consejería del Medioambiente. Unicamente aquellos predios que no pertenecían en la fecha de la transferencia al ICONA, a pesar de encontrarse en trámites de adquisición, continúan dependiendo en la actualidad de la gestión de este organismo a través de su Servicio Territorial en la Comunidad Valenciana. Se trata, en concreto, del monte de Teresa de Cofrentes denominado «Las Pedrizas» de 1.033 hectáreas de extensión, el conocido como «Cabezo» del término de Ayora, que cuenta con 150,5248 hectáreas de cabida y la «Masía Ferreres», radicada en los terminos de Vallibona y Canet lo Roig, cuya superficie real es de 284 hectáreas, a pesar de constar en el Catastro y en el Registro de la Propiedad únicamente con 154,5059 . 


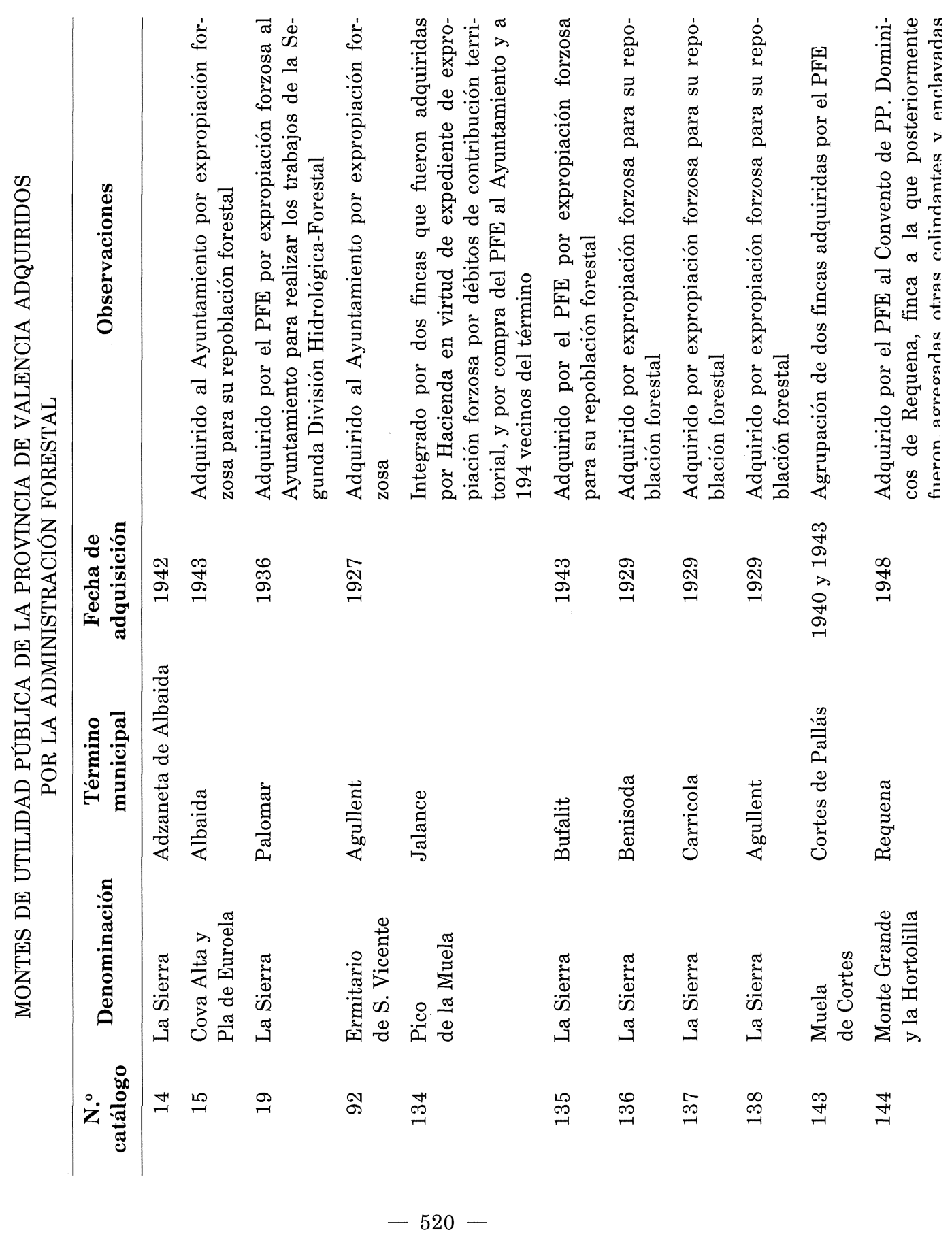


La distribución de las fincas adquiridas por la Administración Forestal del Estado en la región valenciana muestra una evidente concentración en los ya señalados perímetros de repoblación obligatorios y en las comarcas castellonenses más deprimidas, observándose una fuerte disparidad interprovincial en detrimento del espacio alicantino. La razón de este notorio contraste radica en los valores que alcanza el precio del suelo en la provincia de Alicante debido a las expectativas de urbanización que contemplan los actuales propietarios de fincas de uso forestal próximas a los núcleos turísticos de la costa. Esta es, por otra parte, una de las principales causas de la degradación que han sufrido las formaciones vegetales en los municipios de segunda línea del litoral alicantino como los de Pego o Vall de Ebo, donde los propietarios de terreno forestal ven próxima la recalificación del suelo ante el anacronismo de conservar como suelo no urbanizable espacios pedregosos y degradados, al igual que ocurre en municipios de tercera línea que, aunque a más largo plazo, también se platean esta posibilidad, razón por la que la mayor parte de los incendios forestales son, en estos términos, intencionados.

RESUMEN. La defensa del patrimonio forestal público llevada a cabo por los ingenieros de montes en la región valenciana desde finales del siglo xIx, se ha concretado en el saneamiento del estado legal de los predios públicos y en la adquisición de nuevas fincas con objeto de corregir y ampliar el perímetro de aquéllos o de incrementar el patrimonio público.

En el esclarecimiento de las condiciones legales de los montes públicos han desempeñado un papel fundamental los actos de deslinde y amojonamiento, así como las inscripciones en los registros de la propiedad. Por otra parte, los objetivos que han guiado la política de adquisiciones de terreno forestal han estado generalmente relacionados con la ejecución de trabajos de corrección hidrológico-forestal o con la recuperación de fincas forestales en comarcas deprimidas.

RÉSumé. La défense du patrimoine forestier public développée par les ingénieurs forestiers dans la région de Valence depuis la fin du XIX siècle s'est concrétisée dans l'éclaircissement des conditions légales des forets publiques et dans les acquisitions foncières dans le but de corriger et d'agrandir le périmètre des ceux-ci ou d'accroitre le patrimoine public.

Les travaux de délimitation et de bornage, ainsi que les inscriptions dans les régistres de la propriété, ont joué un role fondamental dans l'éclaircissement des conditions légales des forets publiques. D'autre part, les objectifs qui ont orienté la politique d'acquisitions foncières se sont généralement rapportés à l'exécution de travaux de correction hydrologique-forestière ou à la récupération de terrains à vocation forestière dans de contrées marginales. 